UDC 691:620.197

Author: MASSALIMOV Ismail Alexandrovich, Doctor of Engineering, Bashkir State University (BashSU), Scientific and Research Technological Institute of Herbicides of the Academy of Sciences of the Republic of Bashkortostan (SBI «SRTIH AS RB»); Mushnikov str., 13/2-75, Ufa, 450039; ismail_mass@mail.ru;

Author: YANAKHMETOV Marat Rafisovich, Scientific and Production Enterprise «Techproject», engineer of the first category; Mendeleev str., 215/2-47, Ufa, 450071; ymr89@yandex.ru;

Author: CHUYKIN Aleksandr Evgenievich, Ph.D. in Engineering, Ufa State Petroleum Technological University (USPTU), Department «Building constructions»; Mendeleev str., 195, Ufa, 450080; an2100@yandex.ru;

Author: MASSALIMOV Burhan Ismailovich, Graduate Student, Lebedev P.N. Physics Institute, Russian Academy of Sciences; Leninsky Prospect, 63, Moscow, 119991;

b.massalimov@crocusnano.com;

Author: URAKAEV Farit Hisamutdinovich, Doctor of Chemistry, Senior Researcher, V.S. Sobolev Institute of Geology and Mineralogy of the Russian Academy Science; Koptyuga str.3, Novosibirsk, 630090; urakaev@igm.nsc.ru;

Author: URALBEKOV Bolat Muratovich, Ph.D. in Chemistry, Head of the Department, Al-Farabi Kazakh National University; Al-Farabi Avenue 71, Almaty (Kazakhstan), 050040; bulat.ural@gmail.com;

Author: BURKITBAEV Muhambetkali Myrzabaevich, Doctor of Chemistry, Vice Rector, Al-Farabi Kazakh National University; Al-Farabi Avenue 71, Almaty (Kazakhstan), 050040; mukhambetkali.Burkitbayev@kaznu.kz

\title{
HYDROPHOBIZATION OF DENSE AND FINE CONCRETE BY POLYSULFIDE SOLUTIONS
}

Extended Abstract:

The results of research on hydrophobic impregnation of dense concrete with composition "Aquastat» designed for manufacture of road and airfield plates are presented. It was found that after having been treated with waterrepellent agent the concrete sample is resistant to wetting, i.e. it gets hydrophobic properties. At the same time the water absorption of the samples treated for 24 hours at atmospheric pressure is reduced in three times, and soaked for 0.5 hours under vacuum decreases 5.5 times. It was revealed that the hydrophobic properties of fine-grained concrete impregnated with "Aquastat" may be at 
the same level of those of dense concrete based on coarse filler. Substantially increased hydrophobic properties of dense concrete (more than 5 times) allow authors to forecast twice increased service life of road and airfield plates treated by «Aquastat» composition.

Key words: concrete, sulfur, impregnation, hydrophobization, polysulphide.

DOI: dx.doi.org/10.15828/2075-8545-2016-8-5-85-99

MACHINE-READABLE INFORMATION ON CC-LICENSES (HTML-CODE) IN METADATA OF THE PAPER

$<$ a rel="license" href="http://creativecommons.org/licenses/by/4.0/" $><$ img alt="Creative Commons License" style $="$ borderwidth:0" src="https://i.creativecommons.org/l/by/4.0/88x31.png" / $></ \mathrm{a}><$ br $/><$ span xmlns:dct="http://purl.org/dc/ terms/" href="http://purl.org/dc/dcmitype/Text" property="dct:title" rel="dct:type" $>$ Hydrophobization of dense and fine concrete by polysulfide solutions $</$ span $>$ by $<$ a xmlns:cc $="$ http://creativecommons.org/ns\#" href="Nanotehnologii $v$ stroitel'stve $=$ Nanotechnologies in Construction.2016, Vol. 8, no. 5, pp. 85-99. DOI: dx.doi.org/10.15828/2075-8545-20168-5-85-99" property="cc:attributionName" rel="cc:attributionURL" $>$ Massalimov I.A., Yanakhmetov M.R., Chuykin A.E., Massalimov B.I., Urakaev F.H., Uralbekov B.M., Burkitbaev M.M. </a $>$ is licensed under a $<$ a rel="license" href="http:// creativecommons.org/licenses/by $/ 4.0 / ">$ Creative Commons Attribution 4.0 International License $</ \mathrm{a}>$. $<$ br $/>$ Based on a work at $<$ a xmlns:dct="http://purl.org/dc/terms/" href="http://nanobuild.ru/en EN/nanobuild-5-2016" rel="dct:source" $>$ http:// nanobuild.ru/en_EN/nanobuild-5-2016 $</ \mathrm{a}>$. $<\mathrm{br} />$ Permissions beyond the scope of this license may be available at $<$ a xmlns:cc="http://creativecommons.org/ns\#" href="ismail_mass@mail.ru" rel="cc:morePermissions" >ismail_mass@mail. $\mathrm{ru}</ \mathrm{a}>$.

\section{References:}

1. Bazhenov Y.M. Tekhnologiya betona [Concrete Technology]. Moscow, ASV. 2002. 500 p. (In Russian).

2. Gusev B.V. The problems of nanomaterials creation and nanotechnologies development in construction industry. Nanotekhnologii v stroitel'stve: scientific Internet-journal. 2011. Vol. 6. No.6, pp. 6-12. http://www.nanobuild.ru/ru_RU/ journal/Nanobuild_6_2011_RUS.pdf (date of access 01.06.2016). (In Russian).

3. Inozemtsev A., Korolev E.V. Strength of nano-modified high-strength lightweight concrete. Nanotekhnologii v stroitel'stve: scientific Internet-journal. 2011. Vol. 3. No.1,pp.24-38.http://www.nanobuild.ru/ru_RU/journal/Nanobuild_6_2011_ RUS.pdf (date of access 01.06.2016). (In Russian).

4. Korolev E.V. Proshin A.P., Bazhenov Y.M., Sokolov Y.A. Radiatsionno-zashchitnye i korrozionno-stoikie sernye stroitel'nye materialy [Radiation protection and corrosion-resistant construction materials sulfur]. Moscow: «Paleotypes». 2006. 272 p. (In Russian). 
5. Paturoev V.V. Polimerbetony [Polymer concrete]. Moscow, Stroiizdat. 1987. 286 p. (In Russian).

6. Bazhenov Yu.M. Betonopolimery [Polymers of concrete]. Moscow, Stroiizdat. 1983. 472 p. (In Russian).

7. Patent US №5728428 A. Composition for protecting a body of concrete, a process for preparing same, and a method for the protection of a body of concrete. Rusinov A., Rusinov N., Rusinov H. Declared 01.06.1995. Published 17.03.1998.

8. Zaykov D.N. The new generation of Russian waterproofing penetrating materials. Stroitel'nye Materialy [Building Materials]. 2003. No. 12, pp. 20-21. (In Russian).

9. Latysheva L.Y., Smirnov S.V. How to protect against water and dampness. Stroitel'nye Materialy [Building Materials]. 2003. No. 8, pp. 24-25. (In Russian).

10. Musavirov R.S., Massalimov I.A., Babkov V.V., Chuykin A.E., Balobanov M.A., Sharabyrov M.V. Impregnating water-repellent composition-based water soluble sulfur. Stroitel'nye Materialy [Building Materials]. 2003. No.10, pp. 25-27. (In Russian).

11. Massalimov I.A., Volgushev A.N., Chuikin A.E., Khusainov A.N., Mustafin A.G. Long-term protection of building materials coatings based on nanoscale sulfur. Nanotekhnologii v stroitel'stve: scientific Internet-journal. 2010. No. 1, pp. 4558. Available at: http://www.nanobuild.ru/ru_RU/journal/Nanobuild_1_2010_ RUS.pdf (date of access 01.06.2016). (In Russian).

12. Massalimov I.A., Mustafin A.G., Chuikin A.E., Volgushev A.N., Massalimov B.I., Khusainov A.N. The hardening and increasing of the water resistance of concrete coatings based on nanoscale sulfur. Nanotekhnologii v stroitel'stve: scientific Internet-journal. 2010. No. 2, pp. 54-61. Available at: http://www.nanobuild. $\mathrm{ru} / \mathrm{ru}$ _RU/journal/Nanobuild_2_2010_RUS.pdf (date of access 01.06.2016). (In Russian).

13. Massalimov I.A., Yanakhmetov M.R., Chuykin A.E., Mustafin A.G. Protection of Building Constructions with Sulfur Impregnating Solution. Study of Civil Engineering and Architecture (SCEA). June 2013. Vol. 2. Issue 2, pp.19-24.

14. Yanahmetov M.R., Chuykin A.E., Massalimov I.A. Pore structure modification of cement concretes by impregnation with sulfur-containing compounds. Nanotehnologii v stroitel'stve $=$ Nanotechnologies in Construction. 2015, Vol. 7, no. 1, pp. 63-72. DOI: dx.doi.org/10.15828/2075-8545-2015-7-1-63-72.

15. Massalimov I.A., Yanahmetov M.R., Chuykin A.E. Massalimov I.A., Yanakhmetov M.R., Chuykin A.E.Strength and durability of concrete modified by sulfur-based impregnating compounds. Nanotehnologii v stroitel'stve = Nanotechnologies in 
Construction. 2015, Vol. 7, no. 3, pp. 61-75. - DOI: dx.doi.org/10.15828/20758545-2015-7-3-61-75.

16. Patent RF 2243191. Sposob gidrofobizatsii shifera [Method slate hydrophobization]. Massalimov I.A., Babkov V.V., Musavirov R.S., Chuykin A.E., Amirhanov K.S., Mirsaev R.N. Declared 05.04.2002. Published 27.12.2004. (In Russian).

17. Patent RF 2416589. Sostav dlya obrabotki stroitel'nykh materialov i sposob ikh obrabotki [Composition for treatment of construction materials and method of their processing]. Massalimov I.A., Babkov V.V., Mustafin A.G. Declared 23.09.2009. Published 20.04.2011. Bulletin No. 11. (In Russian).

18. The Eurasian application 201400277/28. Sposob obrabotki stroitel'nykh materialov polisul'fidnymi rastvorami [The method of treating building materials polysulfide solution]. Massalimov I.A., Chuykin A.E., Yanahmetov M.R. Declared 03.26.2014. A positive decision on the grant of a patent 26.03.2016. (In Russian).

\section{Dear Colleagues!}

THE REFERENCE TO THIS PAPER HAS THE FOLLOWING CITATION FORMAT:

Massalimov I.A., Yanakhmetov M.R., Chuykin A.E., Massalimov B.I., Urakaev F.H., Uralbekov B.M., Burkitbaev M.M. Hydrophobization of dense and fine concrete by polysulfide solutions. Nanotehnologii v stroitel'stve $=$ Nanotechnologies in Construction. 2016, Vol. 8, no. 5, pp. 85-99. DOI: dx.doi.org/10.15828/2075-85452016-8-5-85-99. (In Russian).

\section{Contact information}

\section{Massalimov Ismail Alexandrovich ismail_mass@mail.ru}


удК 691:620.197

Автор: МАССАЛИМОВ Исмаил Александрович, д-р техн. наук, профессор, Башкирский государственный университет (ФГБОУ ВО БашГУ); зав. лабораторией, Научно-исследовательский технологический институт гербицидов Академии наук Республики Башкортостан (ГБУ «НИТИГ АН РБ»); ул. Мушникова, 13/2-75, г. Уфа, 450039; ismail_mass@mail.ru;

Автор: ЯНАХМЕТОВ Марат Рафисович, инженер 1-й категории, ООО НПП «Техпроект»; ул. Менделеева, 215/2-47, г. Уфа, 450071; ymr89@уandex.ru;

Автор: ЧУЙкИН Александр Евгеньевич, канд. техн. наук, доцент, Уфимский государственный нефтяной технический университет (ФГБОУ ВО УГНТУ), кафедра «Строительные конструкции»; ул. Менделеева, 195, г. Уфа, 450080; an2100@уandex.ru;

Автор: МАССАЛИМОВ Бурхан Исмаилович, аспирант, Физический институт им. П.Н. Лебедева PAН; Ленинский проспект, д. 63, Москва, 119991; b.massalimov@crocusnano.com;

Автор: УРАКАЕВ Фарит Хисамутдинович, д-р хим. наук, вед. научн. сотр., Институт геологии и минералогии имени В.С. Соболева СО РАН; проспект Академика Коптюга, 3, Новосибирск, 630090; urakaev@igm.nsc.ru;

Автор: УРАЛБЕКОВ Болат Муратович, канд. хим. наук, зав. кафедрой, Казахский национальный университет им. аль-Фараби; проспект аль-Фараби, 71, Алматы, Казахстан, 050040;

bulat.ural@gmail.com;

Автор: БУРКИТБАЕВ Мухамбеткали Мырзабаевич, д-р хим. наук, проректор, Казахский национальный университет им. аль-Фараби, проспект аль-Фараби, 71, Алматы, Казахстан, 050040; mukhambetkali.Burkitbayev@kaznu.kz

\section{ГИДРОФОБИЗАЦИЯ ПЛОТНОГО И МЕЛКОЗЕРНИСТОГО БЕТОНОВ ПОЛИСУЛЬФИДНЫМИ РАСТВОРАМИ}

АННОТАЦИЯ К СТАТЬЕ (АВТОРСКОЕ РЕЗЮМЕ, РЕФЕРАТ):

Представлены данные исследований по эффективности гидрофобизации пропиточной композицией «Аквастат» плотного бетона, используемого для изготовления дорожных и аэродромных плит. Установлено, что в результате обработки гидрофобизатором образец бетона перестает смачиваться водой, приобретая гидрофобные свойства, при этом водопоглощение образцов, пропитанных в течение 24 часов при атмосферном давлении, снижается в три раза, а пропитанных под вакуумом в течение 0,5 часов - в 5,5 раз. Выявлено, что по уровню водопоглощения мелкозернистые бетоны, пропитанные «Аквастат", могут соответствовать плотным бетонам на основе крупного заполнителя. Повышение гидрофобности поверхности бетонных дорожных и аэро- 
дромных плит, обработанных составом "Аквастат», и возможность снижения водопоглощения структуры плотного бетона (более чем в 5 раз) позволяет прогнозировать повышение долговечности и увеличение срока службы дорожных изделий и конструкций до 2 раз и более.

Ключевые слова: бетон, сера, пропитка, гидрофобизация, полисульфид.

DOI: dx.doi.org/10.15828/2075-8545-2016-8-5-85-99

МАШИНОЧИТАЕМАЯ ИНФОРМАЦИЯ О СС-ЛИЦЕНЗИИ В МЕТАДАННЫХ СТАТЬИ (HTML-КОД):

< a rel="license" href="http://creativecommons.org/licenses/by/4.0/"><img alt="Лицензия Creative Commons" style="border-width:0" src="https://i.creativecommons.org/l/by/4.0/88x31.png" / $></$ a $><$ br $/>$ Произведение "<span xmlns:dct="http://purl.org/dc/terms/" href="http://purl.org/dc/dcmitype/Text" property="dct:title" $\mathrm{rel}=$ "dct:type" > Гидрофобизация плотного и мелкозернистого бетонов полисульфидными растворами $</$ span $>$ » созданное автором по имени <a xmlns:cc="http://creativecommons.org/ns \#" href="Нанотехнологии в строительстве. - 2016. - Toм 8, № 5. - C. 85-99. - DOI:dx.doi. org/10.15828/2075-8545-2016-8-5-85-99." property="cc:attributionName" re l="cc:attributionURL"> Массалимов И.А., Янахметов М.Р., Чуйкин А.Е., Массалимов Б.И., Уракаев Ф.Х., Уралбеков Б.М., Буркитбаев М.М. </a>, публикуется на условиях <a rel="license" href="http://creativecommons.org/ licenses/by/4.0/">лицензии Creative Commons "Attribution» ("Атрибуция») 4.0 Всемирная $</ \mathrm{a}>$. $<$ br $/>$ Основано на произведении с <a xmlns:dct="http://purl.org/dc/terms/" href="http://nanobuild.ru/ru_RU/nanobuild-5-2016/" rel="dct:source" > http://nanobuild.ru/ru_RU/nanobuild-5-2016/</a $>$. $<$ br $/>$ Разрешения, выходящие за рамки данной лицензии, могут быть доступны на странице <a xmlns:cc="http://creativecommons.org/ns\#" href="ismail_mass@mail.ru" rel="cc:morePermissions">ismail_mass@mail.ru $</ a>$.

адача повышения долговечности дорожных бетонных и железобетонных изделий и конструкций (элементов арочных мостов, водопропускных труб, колец колодцев, лотков, тротуарных и дорожных плит, бордюрных камней и др.), эксплуатирующихся в условиях воздействия неблагоприятных атмосферных факторов и грунтовых вод, весьма актуальна.

Одним из основных параметров, характеризующих долговечность названных изделий и конструкций, является морозостойкость бетона [1]. Высокая морозостойкость бетона должна быть обеспечена для дорожных изделий и конструкций, эксплуатирующихся в климатических условиях большей части Российской Федерации, что обусловлено продолжительным периодом отрицательных температур и многократным числом переходов температуры через $0^{\circ} \mathrm{C}$. В России накоплен большой опыт строительства и эксплуатации автомобильных дорог со сборным

http://nanobuild.ru 
и цементобетонным покрытиями в климатических условиях Сибири, Дальнего Востока и Крайнего Севера, указывающий на необходимость применения современных методов дополнительной защиты цементобетонных покрытий и сборных железобетонных дорожных и аэродромных плит.

Наиболее распространенными способами повышения плотности и долговечности бетонных структур являются: применение высокомарочных цементов, цементов после дополнительного помола или виброактивации; виброуплотнение и вибропрессование бетонной смеси; использование суперпластификаторов и модификаторов бетона, активных и инертных тонкодисперсных наполнителей, нанопорошков и др. [2-3]. Эти способы существенно улучшают эксплуатационные характеристики бетона за счет уменьшения его пористости и повышения прочности, позволяют получать бетоны, удовлетворяющие требованиям изготовления сборных железобетонных конструкций, цементобетонных дорожных и аэродромных покрытий, железобетонных конструкций гидротехнических сооружений.

Улучшить эксплуатационные характеристики бетонов позволяет также применение специальных вяжущих, например, в технологиях серобетонов, полимербетонов, полимерцементных бетонов $[4,5,6]$ и др.

Еще одним из распространенных методов повышения долговечности традиционных цементных бетонов является применение различного рода защитных покрытий, предохраняющих бетонные изделия и конструкции от агрессивных факторов природных и техногенных воздействий. Покрытия, образующие пленку на поверхности изделия или конструкции, позволяют уменьшить количество воды, проникающей в поры бетона. Заполнение пор бетона различными пропиточными составами позволяет обеспечить надежное перекрытие доступа влаги в поровое пространство материала и тем самым защитить материал.

Распространенным методом защиты бетонов в условиях периодического или постоянного воздействия воды является нанесение на поверхность бетона составов, обеспечивающих проникающую гидроизоляцию, таких как «Пенетрон» (США), «Вандекс супер» (Швейцария), «Ксайпекс» (Канада), «Лахта», «Гидро-S», «Гидротэкс», «ПластГидро», «Кристализол», «Акватрон» и «Кальматрон» (все - Россия) [7-9]. Преимуществами указанного типа пропиточных составов в отличие от органических и кремнийорганических покрытий являются: глубина их 
проникновения вглубь бетона (более 10 см) и минеральная природа, обеспечивающие надежную и долговременную защиту бетона. Ограниченное использование гидроизоляции проникающего действия обусловлено относительно высокой стоимостью используемых материалов.

Одним из наиболее простых и технологичных способов повышения долговечности бетона дорожных конструкций является снижение его пористости и водопоглощения на основе модификации порового пространства специальными пропиточными составами - гидрофобизаторами глубокого проникновения. В данной работе в качестве средства долговременной защиты бетона предлагается обработка поверхности бетонных и железобетонных изделий и конструкций серосодержащим пропиточным составом «Аквастат». В наших работах [10-16] были представлены результаты успешного применения названного пропиточного состава для обработки ряда наиболее распространенных пористых неорганических строительных материалов.

Состав «Аквастат» представляет собой серосодержащую жидкость, которая благодаря низкой вязкости при обработке проникает в поровую структуру материала на глубину более 1 см и при последующем высыхании создает в порах материала нерастворимое защитное покрытие [1718], образованное водоотталкивающими наночастицами серы, которые не вымываются водой, растворителями или солевыми растворами.

Результаты исследований физико-механических свойств строительных материалов, пропитанных серосодержащим составом «Аквастат», представленные в работах [10-18], были получены на образцах тяжелых бетонов с водопоглощением по массе 8-12\%, образцах керамического кирпича с водопоглощением по массе $14-15 \%$ и других пористых материалах. В настоящей работе приводятся данные по эффективности снижения водопоглощения плотных цементных бетонов, характеризующихся низким исходным водопоглощением $1-3 \%$, путем гидрофобизации "Аквастатом», названные бетоны используются для изготовления дорожных и аэродромных плит, к которым в силу жестких условий эксплуатации предъявляются повышенные требования по надежности и долговечности.

В нашей работе проведены сравнительные исследования возможности снижения водопоглощения бетона путем пропитки составом «Аквастат» по четырем различным режимам (полное погружение в ванну в течение 1, 4 и 24 часов при нормальных условиях, а также в течение 
0,5 часа в камере при пониженном давлении с предварительным вакуумированием) образцов-кубов с ребром 10 см плотного цементного бетона с исходным средним водопоглощением по массе, равным $2,5 \%$, и мелкозернистого цементного бетона с аналогичным показателем, равным $12,4 \%$.

Водопоглощение по массе контрольных (необработанных) и пропитанных образцов бетона определялось по методике ГОСТ 12730.3-78 «Бетоны. Метод определения водопоглощения» .

Важным показателем накопления влаги в поровой структуре материала, подвергающегося увлажнению атмосферными осадками, является динамика водонасыщения поверхности бетона при действии столба воды, методика проведения испытания по определению названного показателя приведена в работе [12]. В данной работе было изучено изменение водонасыщения образцов мелкозернистого цементного бетона, высушенных при нормальных условиях в течение 3 суток, за определенный интервал времени воздействия столба воды (0-8 часов).

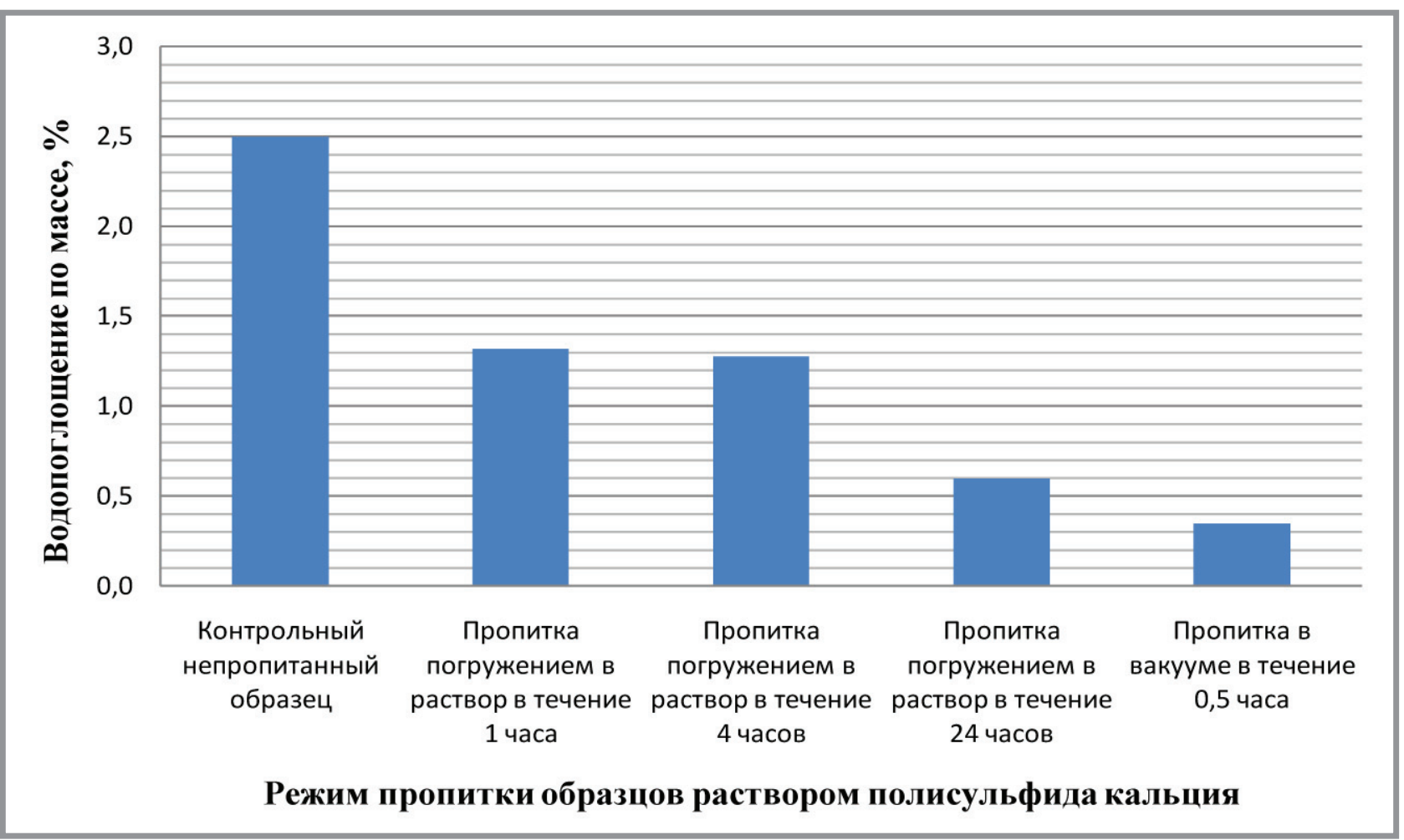

Рис. 1. Влияние режима пропитки раствором полисульфида кальция на водопоглощение по массе образцов плотного цементного бетона 


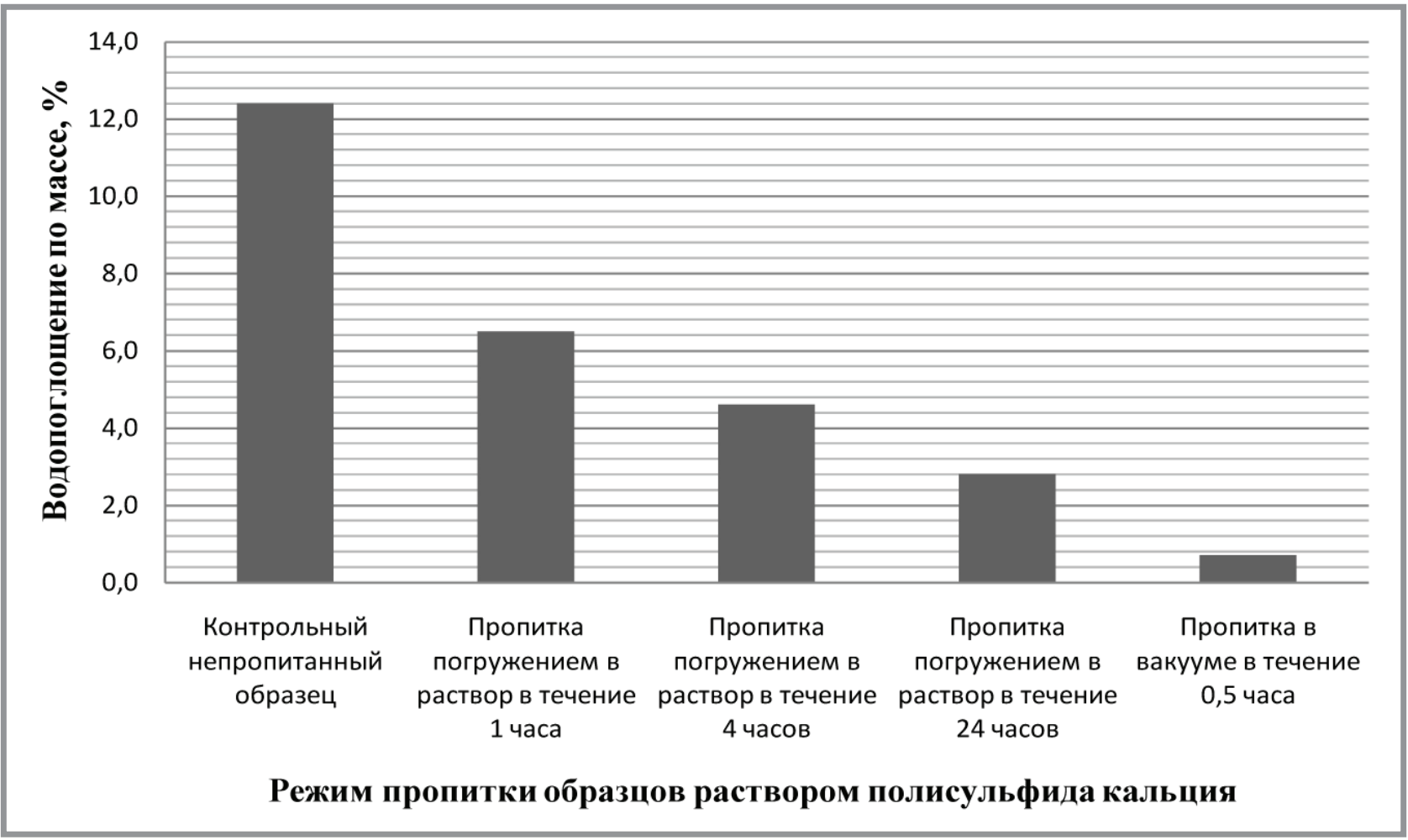

Рuc. 2. Влияние режима пропитки раствором полисульфида кальция на водопоглощение по массе образцов мелкозернистого цементного бетона

Результаты определения водопоглощения по массе для образцов плотного цементного бетона, обработанных пропиточным составом «Аквастат», приведены на рис. 1. Среднее значение водопоглощения по массе контрольных (непропитанных) образцов бетона, равное 2,5\% , в результате пропитки в течение 4 часов снижается на $48 \%$, а выдерживание образцов в ванне с составом в течение 24 часов приводит к снижению этого параметра на 76\% .

24-часовая пропитка образцов бетона обеспечивает более глубокое проникновение пропиточного состава в капиллярные поры цементного камня матрицы бетона и их заполнение при осушении бетона твердой фазой - гидрофобными наночастицами элементной серы. Сократить сроки пропитки и повысить технологичность обработки бетона позволяет пропитка составом «Аквастат» при пониженном давлении с использованием предварительного вакуумирования образцов. В этом случае пропитка образцов бетона в течение 0,5 часа приводит к снижению водопоглощения по массе на 86\% по сравнению с контрольными образцами (рис. 1). 
На рис. 2 приведены аналогичные данные для образцов мелкозернистого бетона с исходным водопоглощением по массе $12,4 \%$. В этом случае так же, как и для плотного цементного бетона, существенное снижение водопоглощения (на $75 \%$ ) обеспечивается при пропитке образцов мелкозернистого бетона в течение 24 часов. При пропитке предварительно вакуумированных образцов мелкозернистого бетона в течение 0,5 часа снижение водопоглощения по массе составляет $94 \%$.

Данные, приведенные на рис. 1 и 2 , показывают, что обработка мелкозернистого бетона составом «Аквастат» позволяет снизить его водопоглощение до уровня, соответствующего плотному бетону, имеющему более высокую стоимость, а также повысить долговечность мелкозернистого бетона, что позволит расширить область его использования для изготовления дорожных изделий и конструкций.

На рис. За приведено изображение скола образца мелкозернистого цементного бетона размером $2 \times 2 \times 2 \mathrm{~cm}$, пропитанного составом «Аквастат» в течение 4 часов при атмосферном давлении. По периметру скола образца отчетливо видна область, в которую проник пропиточный состав и после высыхания образовал водоотталкивающий слой. На рис. Зб
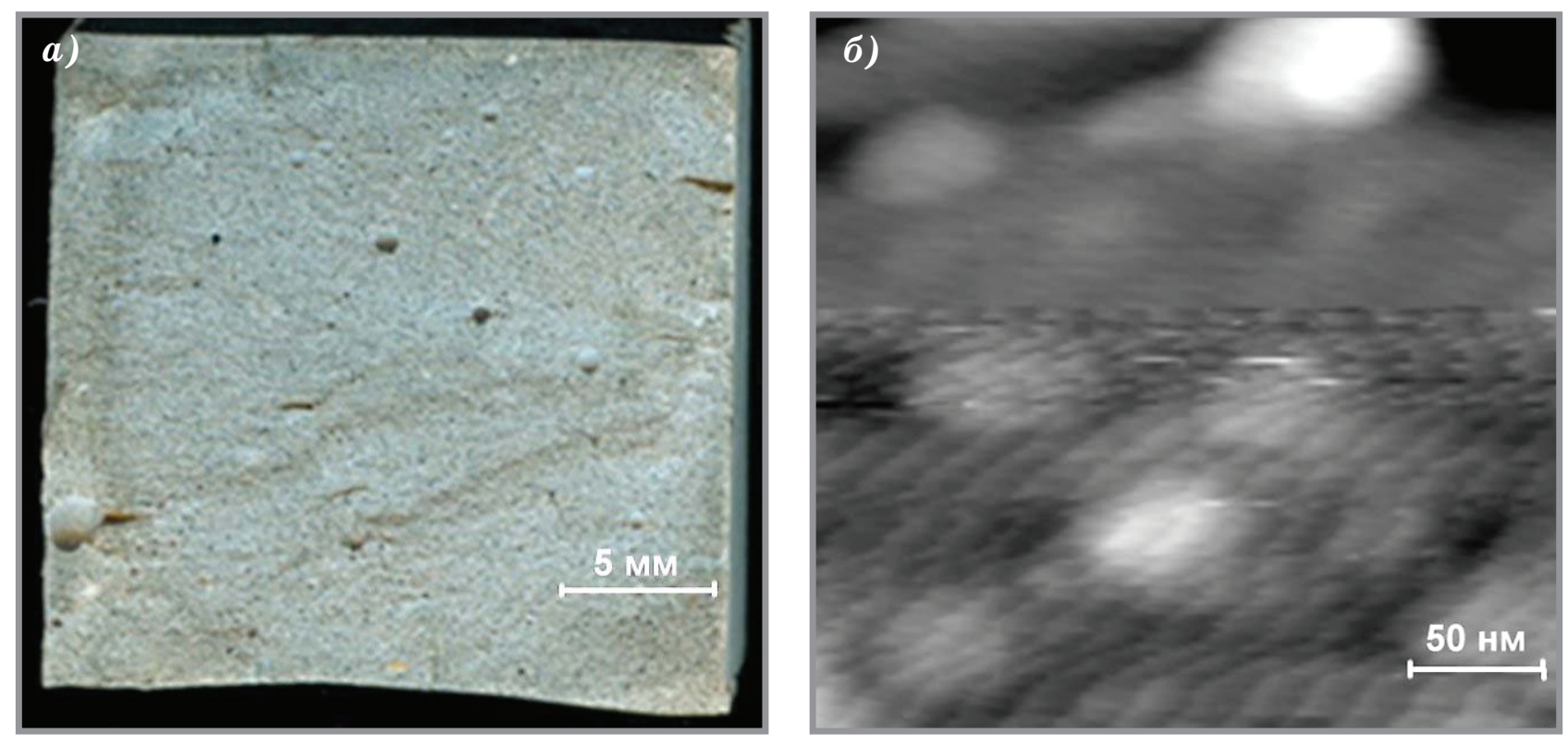

Рис. 3. Изображение скола мелкозернистого цементного бетона, обработанного серосодержащим пропиточным составом «Аквастат»:

a - без увеличения; б - изображение скола бетона, полученное с помощью атомно-силового микроскопа 
приведено изображение структуры скола того же образца мелкозернистого бетона, полученное с помощью атомно-силового микроскопа. На нем видны овальные образования наночастиц серы со средним размером 50 нм, отсутствующие на изображении структуры скола непропитанного бетона. Таким образом, можно предположить, что наличие в поровом пространстве цементного камня матрицы бетона гидрофобных наночастиц серы является причиной предотвращения проникновения воды в поры бетона, снижения водопоглощения и повышения морозостойкости и долговечности цементных бетонов.

На рис. 4 приведены кривые изменения удельного водопоглощения образцов мелкозернистого цементного бетона $(\mathrm{B} / Ц=0,5)$, пропитанных составом "Аквастат» по вышеназванным режимам, за 8 часов воздействия столба воды. Результаты исследований (рис. 4) показывают, что пропитка образцов при нормальных условиях в течение 1 часа приводит

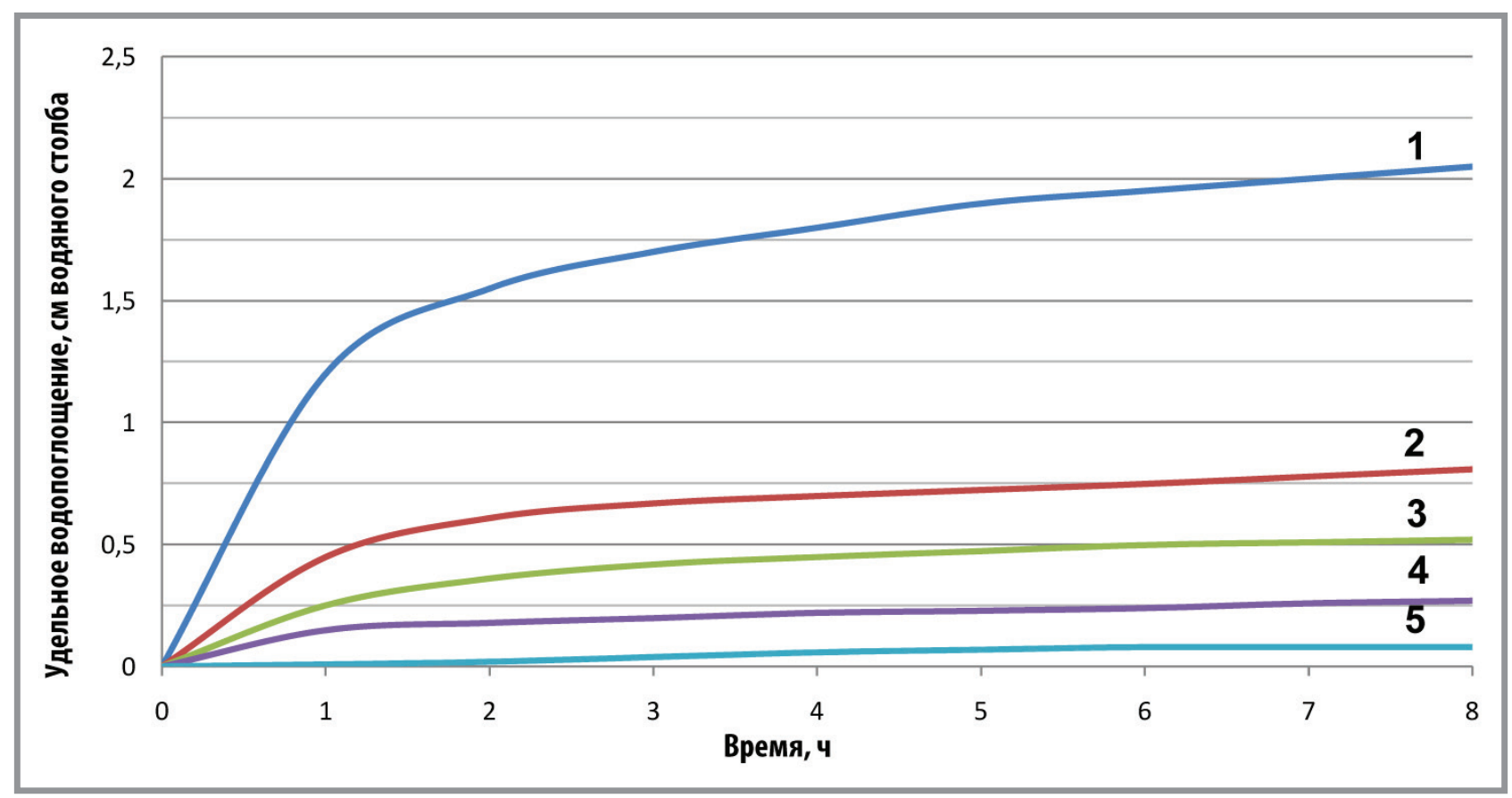

Рис. 4. Динамика изменения удельного водопоглощения образцов мелкозернистого цементного бетона $(\mathrm{B} / Ц=0,5)$, пропитанных составом "Аквастат" по различным режимам:

1 - непропитанный (контрольный) образец мелкозернистого бетона; 2 - образец мелкозернистого бетона, пропитанный в течение 1 ч полным погружением в раствор; 3 - то же, в течение 4 ч; 4 - то же, в течение 24 ч; 5 - образец мелкозернистого бетона, пропитанный в вакууме в течение 0,5 ч 
к двукратному снижению удельного водопоглощения бетона, а пропитка при пониженном давлении вакуумированных образцов обеспечивает 25-кратное снижение удельного водопоглощения. Обработанный составом «Аквастат» бетон становится практически водонепроницаемым в условиях статического давления столба воды.

Таким образом, полученные результаты исследований позволяют сделать вывод о значительной эффективности применения состава «Аквастат» для пропитки цементных бетонов, изделий и конструкций на их основе, а также рекомендовать этот способ гидрофобизации с целью повышения долговечности дорожных бетонных и железобетонных изделий и конструкций, железобетонных аэродромных плит и конструкций гидротехнических сооружений.

Работа поддержана ПЦФ Республики Казахстан и Российскил фондом содействия развитию малых форл предприятий в научно-технической сфере.

УВАЖАЕМЫЕ КОЛЛЕГИ!

ПРИ ИСПОЛЬЗОВАНИИ МАТЕРИАЛА ДАННОЙ СТАТЬИ

ПРОСИМ ДЕЛАТЬ БИБЛИОГРАФИЧЕСКУЮ ССЫЛКУ НА НЕЁ:

Массалилов И.А., Янахлетов М.Р., Чуйкин А.Е., Массалилов Б.И., Уракаев Ф.Х., Уралбеков Б.М., Буркитбаев М.М. Гидрофобизация плотного и мелкозернистого бетонов полисульфидными растворами // Нанотехнологии в строительстве. - 2016. - Том 8, № 5. - C. 85-99. - DOI: dx.doi. org/10.15828/2075-8545-2016-8-5-85-99.

\section{DeAr COlleagues!}

THE REFERENCE TO THIS PAPER HAS THE FOLLOWING CITATION FORMAT:

Massalimov I.A., Yanakhmetov M.R., Chuykin A.E., Massalimov B.I., Urakaev F.H., Uralbekov B.M., Burkitbaev M.M. Hydrophobization of dense and fine concrete by polysulfide solutions. Nanotehnologii v stroitel'stve = Nanotechnologies in Construction. 2016, Vol. 8, no. 5, pp. 85-99. DOI: dx.doi.org/10.15828/2075-85452016-8-5-85-99. (In Russian). 


\section{Библиографический список:}

1. Баженов Ю.М. Технология бетона. - М.: АСВ, 2002. -500 с.

2. Гусев Б.В. Нанотехнологиям в строительстве быть // Нанотехнологии в строительстве. - 2011. - Toм 3, № 6. - C. 6-12. - URL: http://www.nanobuild.ru/ ru_RU/journal/Nanobuild_6_2011_RUS.pdf (дата обращения 01.06.2016).

3. Инозелиев A.C., Королев E.В. Прочность наномодифицированных высокопрочных легких бетонов // Нанотехнологии в строительстве. - 2011. - Том 3, № 1. C. 24-38.-URL:http://www.nanobuild.ru/ru_RU/journal/Nanobuild_6_2011_ RUS.pdf (дата обращения 01.06.2016).

4. Радиационно-защитные и коррозионно-стойкие серные строительные материалы / Е.В. Королев, А.П. Прошин, Ю.М. Баженов, Ю.А. Соколова. - М.: Палеотип, 2006. - 272 с.

5. Патуроев В.В. Полимербетоны. - М.: Стройиздат, 1987. - 286 с.

6. Баженов Ю.М. Бетонополимеры. - М.: Стройиздат, 1983. - 472 с.

7. Rusinov A., Rusinov N., Rusinov H. Composition for protecting a body of concrete, a process for preparing same, and a method for the protection of a body of concrete // Patent US № 5728428 A. Declared 01.06.1995. Published 17.03.1998.

8. Зайков Д.Н. Новое поколение российских гидроизоляционных материалов проникающего действия // Строительные материалы. - 2003. - № 12. C. 20-21.

9. Латышева Л.Ю., Слирнов С.В. Как защититься от воды и сырости // Строительные материалы. - 2003. - № 8. - С. 24-25.

10. Пропиточные гидрофобизирующие композиции на основе водорастворимой серы / Р.С. Мусавиров, И.А. Массалимов, А.Е. Чуйкин, В.В. Бабков, М.А. Балобанов, М.В. Шарабыров // Строительные материалы. - 2003. - № 10. C. $25-27$.

11. Массалилов И.А., Волгушев А.Н., Чуйкин А.Е., Хусаинов А.Н., Мустафин А.Г. Долговременная защита строительных материалов покрытиями на основе наноразмерной серы // Нанотехнологии в строительстве. - 2010. - Т.2, № 1. C. 45-58. - URL: http://www.nanobuild.ru/ru_RU/journal/Nanobuild_1_2010_ RUS.pdf (дата обращения 01.06.2016).

12. Массалилов И.А., Мустафин А.Г., Чуйкин А.Е., Волгушев А.Н., Массалимов Б.И., Хусаинов А.Н. Упрочнение и увеличение водонепроницаемости бетона покрытиями на основе наноразмерной серы // Нанотехнологии в строительстве. - 2010. - T. 2, № 2. - C. 54-61. - URL: http://www.nanobuild.ru/ru_RU/ journal/Nanobuild_7_2010_RUS.pdf (дата обращения 01.06.2016). 
13. Massalimov I.A., Yanakhmetov M.R., Chuykin A.E., Mustafin A.G. Protection of Building Constructions with Sulfur Impregnating Solution. Study of Civil Engineering and Architecture (SCEA). June 2013. Vol. 2. Issue 2, pp.19-24.

14. Янахлетов М.Р., Чуйкин А.Е., Массалилов И.А. Модифицирование поровой структуры цементных бетонов пропиткой серосодержащими растворами / Н Ннотехнологии в строительстве. - 2015. - Tом 7, № 1. - C. 63-72. - DOI: dx.doi. org/10.15828/2075-8545-2015-7-1-63-72.

15. Массалилов И.А., Янахлетов М.Р., Чуйкин А.Е. Прочность и долговечность бетона, модифицированного пропиточными составами на основе серы // Нанотехнологии в строительстве. - 2015. - Tом 7, № 3. - C. 61-75. - DOI: dx.doi. org/10.15828/2075-8545-2015-7-3-61-77.

16. Массалилов И.А., Бабков В.В., Мусавиров Р.С., Чуйкин А. Е., Алирханов К.Ш., Мирсаев Р.Н. Способ гидрофобизации шифера // Патент РФ 2243191. Заявл. 05.04.2002. Опубл. 27.12.2004.

17. Массалимов И.А., Бабков В.В., Мустафин А.Г. Состав для обработки строительных материалов и способ их обработки // Патент РФ 2416589. Заявл. 23.09.2009. Опубл. 20.04.2011. Бюл. № 11.

18. Массалилов И.А., Чуйкин А.Е., Янахлетов М.Р. Способ обработки строительных материалов полисульфидными растворами // Евразийская заявка 201400277/28. Заявл. 26.03.2014. Положительное решение на получение патента 26.03.2016. ismail_mass@mail.ru 